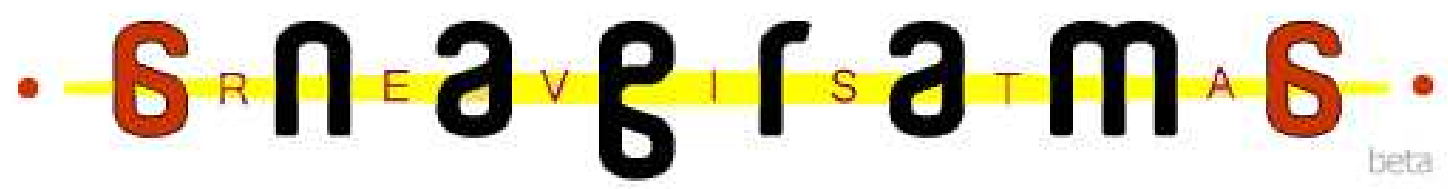

\section{Cultura Marginal na Metrópole: manifestações e apropriações do espaço urbano na região sul de São Paulo}

Bruno José Albuquerque Almeida Barbosa

\section{Resumo}

O sentimento político-social sedimentado na história de comunidades periféricas, unido ao posicionamento marginal destes grupos sociais culminou no surgimento de uma rede de produção cultural independente cuja novidade consiste na representação e divulgação de uma identidade local. Esta nova manifestação cultural urbana tem como marca o ambiente, as localidades identificadas como periferia da metrópole. Elas acontecem em locais públicos, como a rua, ou em locais coletivos de acesso público. Partimos então da hipótese de que a interação entre estas redes de cultura e os espaços onde elas acontecem são mutuamente condicionados, dialeticamente, nascendo do lugar a cultura, e da cultura um espaço de apropriação por parte dos moradores e frequentadores.

Palauras-chave: São Paulo; Cultura marginal; Periferia; Espaço urbano.

\section{IกTRODUÇח̃O}

Desde a segunda metade do século XIX, quando a maioria das atuais metrópoles brasileiras começou a apresentar altas taxas de crescimento ao mesmo tempo em que a industrialização se desenvolveu e a modernização da cidade por isso se impôs, as classes de mais alta renda começaram a exibir um processo de segregação que segue, até hoje, a mesma tendência. Fatores de ordem cultural, associados aos atrativos do sítio natural, e a localização, principalmente em termos de acessibilidade ao centro, tem ditado a espacialização desta tendência. Através da segregação, as camadas mais abastadas dominam o espaço urbano, não só produzindo suas áreas residenciais nas regiões mais

\footnotetext{
${ }^{1}$ Estudante de graduação $5^{\circ}$ semestre do curso de Arquitetura e Urbanismo da Universidade Anhembi Morumbi.
} 
agradáveis e bem localizadas, mas também atuando sobre toda a estrutura urbana segundo seus interesses (SANTOS, 1990; VILLAÇA, 1997). O caráter excludente destes processos arrastou as parcelas da população de menor renda para as bordas das aglomerações urbanas, onde se instalaram e desenvolveram comunidades distantes dos aparatos e regularidades da cidade formalizada. Para ter uma ideia da permanência e dimensão deste quadro, os habitantes do município de São Paulo, em 2008, que viviam em favelas, núcleos ou loteamentos irregulares somavam 31,83\%, 3.448 .562 pessoas em 892.227 domicílios nestas condições (SEADE, 2008).

\begin{abstract}
A segregação urbana ou ambiental é uma das faces mais importantes da desigualdade social e parte promotora da mesma. À dificuldade de acesso aos serviços de saúde e infraestrutura urbanos (transporte precário, saneamento deficiente, drenagem inexistente, dificuldade de abastecimento, difícil acesso aos serviços de saúde, educação e creches, maior exposição à ocorrência de enchentes e desmoronamentos, etc.) somam-se menos oportunidades de emprego (particularmente do emprego formal), menos oportunidades de profissionalização, maior exposição à violência (marginal ou policial), discriminação contra mulheres e crianças, difícil acesso à justiça oficial, difícil acesso ao lazer. A lista é interminável (MARICATO, 1996, p. 56).
\end{abstract}

Diante deste quadro de precariedade ambiental e exclusão social nas áreas periféricas das grandes cidades brasileiras, surgiu a emergência de movimentos sociais em reivindicação, frente ao Estado, pela implantação de infraestrutura urbana nestes assentamentos. Comunidades políticas independentes surgiram com a proliferação das Associações de Moradores e se voltaram para a busca de uma melhor qualidade de vida pela adequação do espaço urbano às suas necessidades (DURHAM, 1988). As periferias se consolidaram então como fenômeno político e sociocultural e, consequentemente, como objeto de estudo e perspectiva teórica. Áreas periféricas foram tomadas como local de pesquisa, buscando compreender detidamente redes de parentesco e de vizinhança, modos de vida, estratégias de sobrevivência, formas de sociabilidade e representações políticas (FRÚGOLI JR, 2005).

De uma perspectiva contemporânea, o sentimento político-social citado anteriormente, já sedimentado nas comunidades periféricas, unido ao posicionamento marginal destes grupos sociais culminou no surgimento de uma rede de produção cultural independente cuja novidade consiste na representação e divulgação da identidade local. Em áreas de ausência de equipamentos de mercado cultural a produção e manifestação de artistas e grupos periféricos, como o hip-hop, o grafite, e a "literatura marginal" (NASCIMENTO, 2006), começam a tomar importância e se equiparam em termos de 
visibilidade e aceitação entre as demais manifestações urbanas centrais. Essas manifestações se desenvolvem ao mesmo tempo 'a partir de' e 'como resposta a' uma condição de desigualdade social e passa a figurar como um importante elemento de mobilização das pessoas que partilham desta cultura e também como ferramenta de comunicação com a sociedade.

Esta nova manifestação cultural urbana tem como marca o ambiente, as localidades identificadas como periferia da metrópole. Elas acontecem em locais públicos, como a rua, ou em locais coletivos de acesso público. Partimos então da hipótese de que a interação entre estas redes de cultura e os espaços onde elas acontecem são mutuamente condicionados, nascendo do lugar a cultura, e da cultura um espaço de apropriação por parte dos moradores e frequentadores em uma relação dialética. As formas de usos dos territórios pelas manifestações culturais e o seus reflexos nos assentamentos que serão abordados tornam-se então um importante objeto de pesquisa, na perspectiva de compreender a importância destas associações para o desenvolvimento de comunidades e áreas urbanas.

\section{SEGREGAÇÃO E CONFIחAMTERTO MA METRÓPOLE CAPITALISTA}

Dentre os inúmeros diagnósticos sobre as transformações em curso nas atuais metrópoles, Magnani (1998) cita que se podem distinguir duas visões principais. Uma, já anteriormente descrita na citação de Maricato (1996), enfatiza os aspectos desagregadores do processo com base em variáveis e indicadores de ordens sociológicas, econômicas e demográficas. A outra visão refere-se a novas tendências de socialização que têm se disseminado com o crescimento de redes e pontos de encontros virtuais e com uma maior suscetibilidade a simulacros e apelos publicitários, assim estabelecendo uma nova formatação de valores sociais.

Na primeira visão, mostra-se uma continuidade evolutiva, onde os fatores de crescimento, desordenados, terminam por produzir inevitavelmente o caos urbano; na segunda, enfatizase a ruptura, resultado de um salto tecnológico que tornou obsoletas não só as estruturas urbanas anteriores como as formas de comunicação e sociabilidade a elas correspondentes. Uma, fruto do capitalismo selvagem; a outra, identificada com o capitalismo tardio. Ainda que por motivos diferentes, essas duas perspectivas - aqui polarizadas para efeito comparativo e de contraste - levam a conclusões semelhantes no plano da cultura urbana: deterioração dos espaços e equipamentos públicos, com a consequente privatização da vida coletiva, segregação, evitação de contatos face-a-face, confinamento em ambientes e redes sociais restritos (MAGNANI, 1998: 58). 
Partimos então da premissa de que estes processos que cunharam a metrópole atual fragmentaram a cidade e desenvolveram uma sociabilidade que distingue sua população em camadas menos ou mais abastadas. A dimensão pública perdeu sua dimensão política de contrato social e reduziu-se à administração do trânsito, da rede de água e de esgoto, etc. O espaço público diminui de tamanho ao ser capturado e privatizado, esvazia-se sua dimensão coletiva e seu uso multifuncional. Resta apenas aquele necessário à circulação de mercadorias, inclusive mercadorias humanas. Os mais ricos eliminam distâncias com o automóvel e com o telefone, e a sociabilidade se exerce entre parentes e amigos dispersos pela cidade. A casa ou apartamento, isolados e autossuficientes, limitam um espaço social que não é complementado pela vizinhança. Na periferia, ao contrário, a vizinhança e o bairro constituem locais privilegiados para a formação de redes e sociabilidade (DURHAM, 1988; ROLNIK, 2000). Este privilégio está associado à já abordada necessidade de organização para a luta por benefícios e melhorias do espaço urbano que atendem a "cidade formal", mas não percorrem as longas distâncias que levam à periferia. As ações políticas-sociais surgem então em redes de sociabilidade como focos de resistência no sentido contrário à tendência da desordem urbana.

\section{FOCOS DE RESISTÊกCIA}

Sem a intenção de conceituar o que é cultura, mas recorrendo à disciplina que trata especificamente desta questão, a antropologia, podemos verificar a ideia de que toda organização social humana, toda comunidade possui sua maneira de se manifestar culturalmente $^{2}$. Tomando Lévi-Strauss como referência moderna da compreensão antropológica de cultura, verificamos que sua abordagem parte da produção de cultura como 'natureza' humana e forma de organização, resistência e sobrevivência das sociedades e dos grupos perante seu meio (LÉVI-STRAUSS, 1972). Desta maneira, a produção de formas específicas de arte e socialização está associada à identidade e autonomia de grupos sociais, o que nos leva a buscar compreender, nas comunidades estudadas, a relação entre esta emancipação política-social, através de suas ações culturais, e a precariedade do espaço que a conformou.

${ }^{2}$ Esta problemática foi tratada de maneira exaustiva em Roque de Barros, Laraia. Cultura, um conceito antropológico. Rio de Janeiro, Jorge Zahar, 1988 e pode ser acessado em http://www.taddei.eco.ufrj.br/AntCom/Laraia.pdf 
Buscando a natureza dessa experiência cultural sobre o espaço urbano em que comunidades periféricas estão assentadas e em que situações ela pode ser identificada seguiu-se uma metodologia proposta por Magnani (1998) que consiste em (a) descrever recortes no espaço, (b) recostes estes que são significativos em virtude de práticas e formas de apropriação por parte dos agentes, (c) e que terminam por determinar padrões coletivos de comportamento e regras de sociabilidade.

Diante das diversas áreas, dentro da Região Metropolitana de São Paulo, onde a urbanização precária pode ser verificada, algumas delas possuem uma manifestação cultural independente muito organizada e desenvolvida. Este é o caso do chamado "Triângulo da Morte", região do entroncamento entre os distritos Jardim Ângela, Capão Redondo e Jardim São Luís, a pejorativa alcunha deve-se ao alto índice de violência que assola a localidade. Foi nesta parcela periférica, no sudoeste da cidade de São Paulo, carente de infraestrutura urbana e equipamentos públicos, que se concentraram práticas independentes de produção literária que buscavam descrever o cotidiano da vida na periferia. A identidade comunitária que surgiu a partir dos textos que retratavam uma realidade, escritos por quem vivia e ainda vive esta realidade, embasou a proliferação de ações políticas-sociais. Estas se propuseram à recuperação da dignidade das populações periféricas, assim como os movimentos sociais sempre presentes nestas regiões, mas seguindo uma linha artístico-cultural.

Uma das vertentes mais presentes nestas ações é o trabalho desenvolvido para a inserção social e o desenvolvimento educacional de crianças usando a literatura, o cinema e outras formas de manifestação artística como ferramenta. Os atores sociais organizadores destas ações assumem a responsabilidade sobre o tempo livre das crianças e sobre sua permanência no espaço público das comunidades. As favelas Jardim Comercial I e Jardim Ibirapuera, localizadas nos distritos Capão Redondo e Jardim São Luís, respectivamente, abrigam representações que desenvolvem um significativo trabalho neste sentido.

\section{JARDIM COMERCIAL I - ONG IOTERFERÊกCIA}

O Jardim Comercial I se estabeleceu no leito do córrego da Moenda, em um terreno de propriedade pública municipal, e expandiu-se na área de várzea de seus afluentes havendo uma estimativa, em 2011, de 1.372 imóveis. Sua ocupação se iniciou em 1972 nesta região próxima à Estrada de Itapecerica e que, hoje, está sob jurisdição administrativa da Subprefeitura de Campo Limpo. De acordo com o atual Plano Diretor 
(2002) do município, 95\% de sua área estão zoneadas como ZEIS $1^{3}$, mas ainda não há plano de urbanização para a comunidade (HABISP, 2011).

Em 2009, dentre as inúmeras vielas e passagens que cortam as casas nesta comunidade, em uma parceria entre Ferréz, criado no Jardim comercial I e escritor do movimento "Marginal", e a ONG Casa do Zezinho, que atua com crianças em situação de vulnerabilidade social na região do "Triângulo da Morte", foi adquirido um imóvel na Travessa Santiago, que dá acesso à favela a partir da Rua Eurico Branco Ribeiro. A proposta inicial era criar um espaço para a leitura direcionado às crianças que passavam seu tempo livre na travessa, assim nasceu a Associação Educacional e Assistencial Interferência, ou apenas ONG Interferência. Durante muitos meses o imóvel permaneceu aberto apenas aos sábados, o suficiente para que as crianças se apropriassem do espaço e adquirissem o hábito da leitura. Durante este período, Férrez sentiu a necessidade de inserir atividades artísticas na ONG, o que foi possível com a chegada da pedagoga Evanise da Silva. Com isso o espaço passou a funcionar de segunda a sábado e assumiu um papel complementar à educação formal que as crianças recebem na escola, mas com uma proposta lúdica para estimular as atividades desenvolvidas.

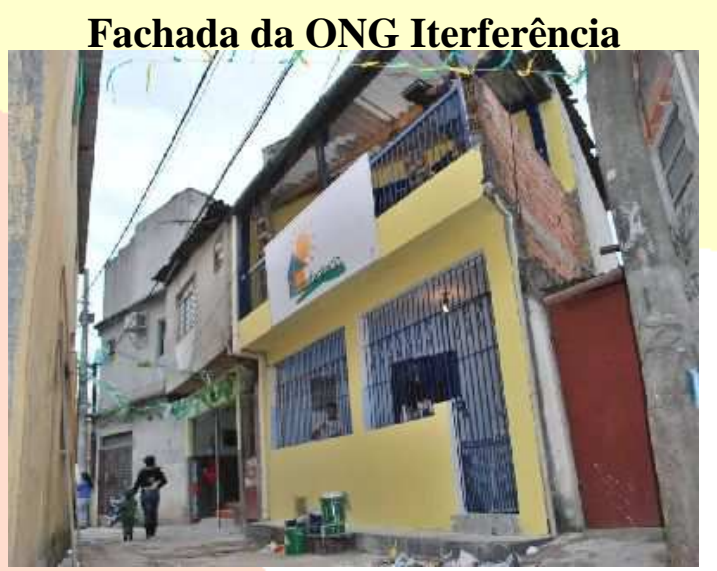

Fonte: http://ferrez.blogspot.com.br

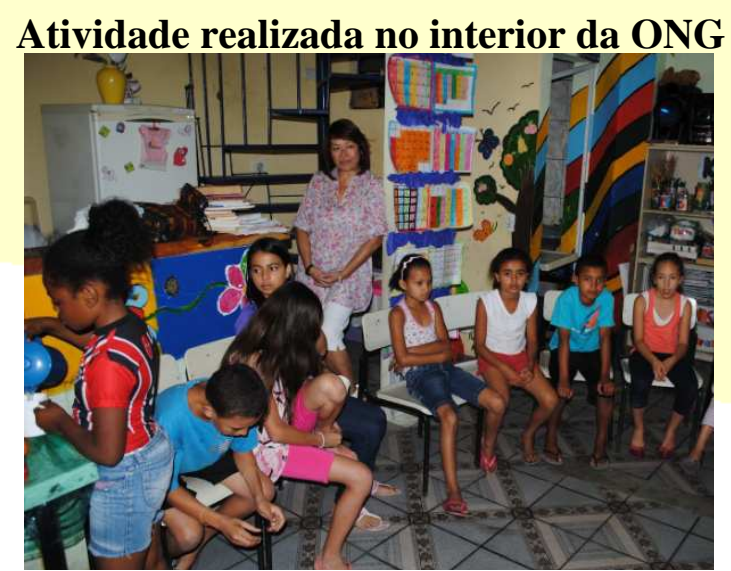

Fonte: http://ferrez.blogspot.com.br

\section{JARDIII IBIRAPUERA - UIELA LETRAS E LIUROS}

A proximidade com a Marginal Pinheiros e com linhas da CPTM e do Metrô faz o Jardim Ibirapuera apresentar índices de infraestrutura urbana ligeiramente mais elevados

${ }^{3}$ Zona Especial de Interesse Social: são porções do território destinadas, prioritariamente, à recuperação urbanística, à regularização fundiária e produção de Habitações de Interesse Social - HIS ou do Mercado Popular - HMP, incluindo a recuperação de imóveis degradados, a provisão de equipamentos sociais e culturais, espaços públicos, serviço e comércio de caráter local. 
em comparação com o Jardim Comercial I. Isto ocorre porque quanto mais próximo da "cidade formal" mais a comunidade pode usufruir dos aparatos que beneficiam esta. A favela Jardim Ibirapuera, também conhecida como Erundina ou Pinhal, encontra-se dentro do perímetro da Subprefeitura de M’Boi Mirim, no distrito Jardim São Luís, e abriga, em dados de 2011, aproximadamente 1.498 domicílios. Sua ocupação iniciou-se em 1968 em um terreno de propriedade pública municipal e topografia acidentada. Sem plano de urbanização, a comunidade possui 98\% do seu território sob ZEIS 1 de acordo com o Plano Diretor de 2002 do município (HABISP, 2011).

De forma mais independente que a ONG Interferência, dois moradores do Jardim Ibirapuera também usaram a literatura para dar usos mais significativos ao tempo livre das crianças da favela. Com um projetor de vídeos obsoleto que havia na comunidade, Anderson 'Buiu' e Joseh Sillva propuseram a exibição de filmes em uma das vielas próximas a suas casas, na altura do número 20 da Rua Macedônio Fernandez. A ideia era muito simples, além do projetor apenas um tecido branco para a projeção, as crianças sentariam nos degraus da viela. Empolgados com a proposta os moradores, espontaneamente, doaram pipoca, refrigerantes e copos descartáveis para o evento que foi o estopim para uma série de ações sociais organizadas pelos dois amigos na comunidade. Mantendo as sessões de cinema e tendo as crianças cada vez mais inseridas na ação social, sentiu-se a necessidade de explorar novas atividades que poderiam ser desenvolvidas na viela.

Exibição de filme na viela.

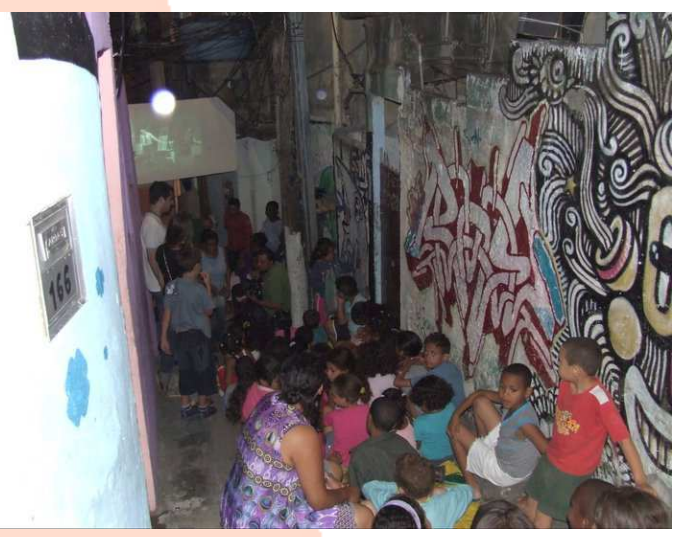

Fonte: http://vielaletraselivros.blogspot.com

\section{Crianças assistem a filme na viela.}

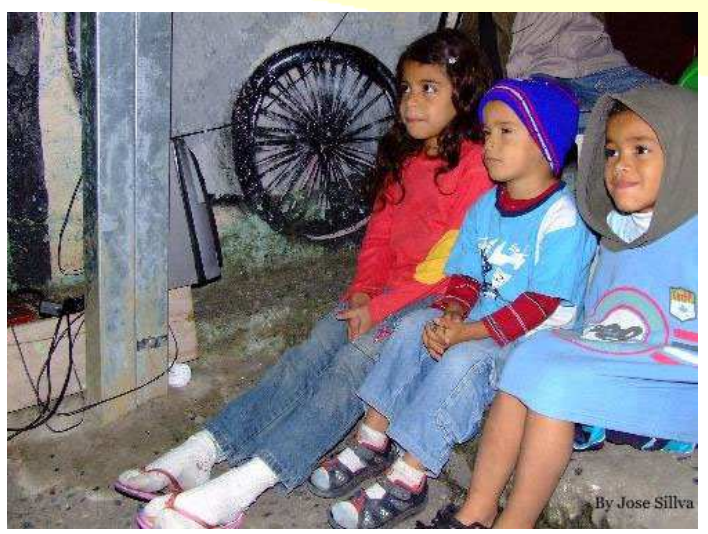

Fonte: http://vielaletraselivros.blogspot.com

Diante de um quadro defasado de alfabetização entre as crianças, foram propostas rodas de leitura para que o interesse na literatura fosse estimulado. Os livros se tornaram o 
elemento centralizador da ação, sendo presença obrigatória em qualquer outra atividade. Antes do filme e antes do jogo de futebol havia a roda de leitura, nascia assim o "Viela Letras e Livros". O resultado foi o esperado, e a necessidade de uma biblioteca na viela surgiu para atender o desejo das crianças e dos idealizadores. Tábuas de madeira apoiadas nos pilares expostos de diferentes casas, pronto, era só preencher com livros e a biblioteca estava lá, adornada com as paredes coloridas pelas oficinas de pintura e dividindo espaço com as fotografias tiradas pelas próprias crianças. Se a viela fica pequena, a ação toma conta da rua. Se chove, alguma casa ou a igreja evangélica da proximidade abrem suas portas.

Atividades realizadas como parte do

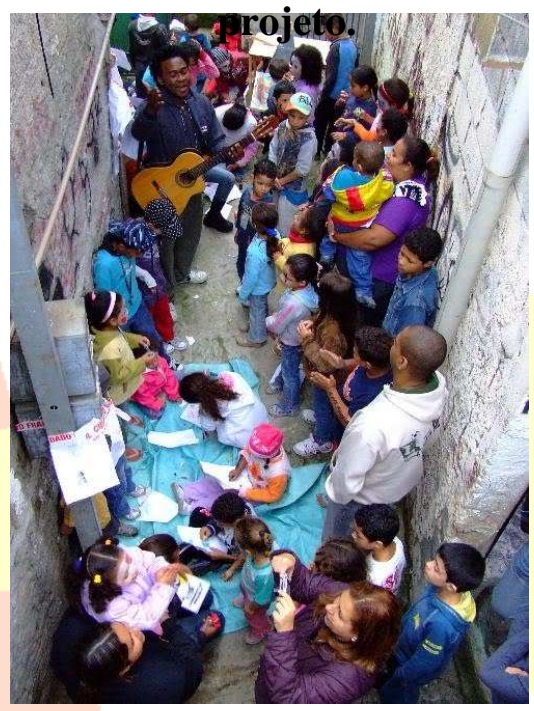

Fonte: http://vielaletraselivros.blogspot.com
Biblioteca criada na viela.

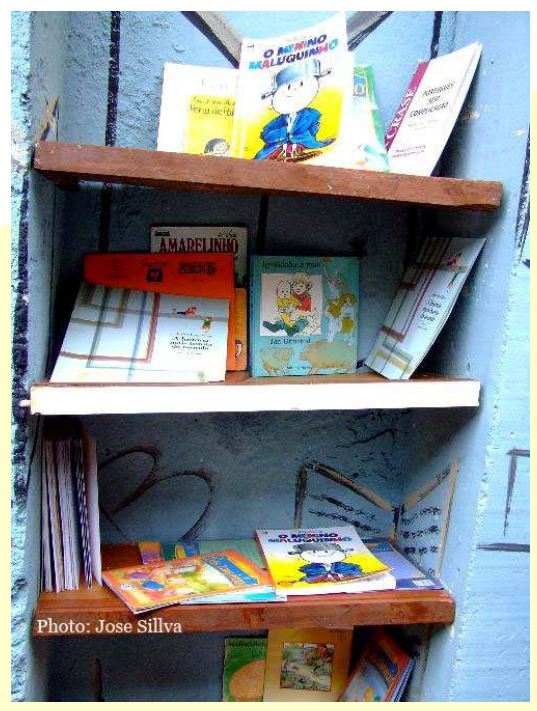

Fonte: http://vielaletraselivros.blogspot.com

\section{RELAÇÔES ERTRE MANIFESTAÇÔES E ESPAÇOS}

Analisando mais especificamente as ligações existentes entre estas manifestações de cultura e a configuração do espaço urbano em que estão inseridas foi possível identificar determinadas práticas, que salientaram pontos em comum e assim pode-se chegar a uma melhor compreensão destas relações.

Dentre as atividades desenvolvidas no projeto Viela Letras e Livros existe o Futebol \& Leitura, consiste de uma ideia simples: roda de leitura antes do jogo de futebol entre as crianças. Porém a viela, estreita e formada por degraus irregulares, torna a prática inviável de se realizar no que chamaremos de base das ações, o lugar que recebe a agenda mais frequente de atividades e de onde partem as demais atividades desenvolvidas. Isso fez com que fosse preciso buscar espaços que atendessem o mínimo exigido para a prática do 
esporte. Durante os finais de semana é possível utilizar as quadras poliesportivas das escolas públicas da região da favela, como a Escola Estadual Comendador Alfredo Vianello Gregório e a Escola Municipal de Ensino Infantil Gen de Gaulle. Diante disto foi possível realizar os jogos utilizando equipamentos públicos de uso específico, mas que ganharam novos significados com a inserção da proposta dos idealizadores e, assim, de uma identidade comunitária mais forte.

\section{Roda de leitura na quadra da Escola Com. Alfredo Vianello Gregório.}

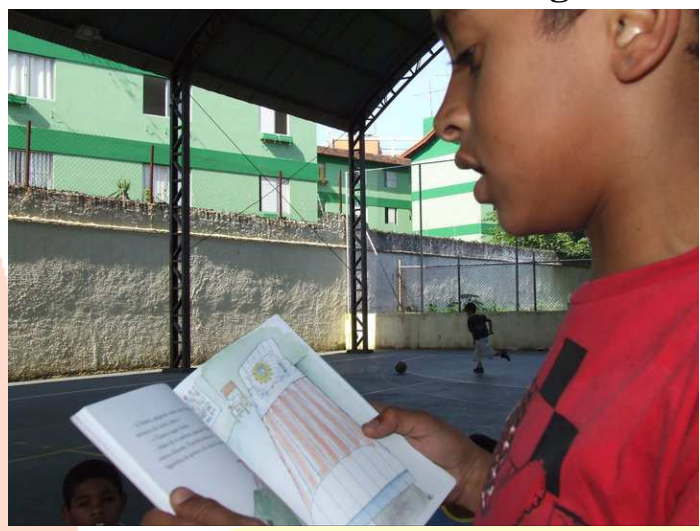

Fonte: http://vielaletraselivros.blogspot.com

\section{Crianças se reunem na quadra da Escola Gen de Gaulle.}

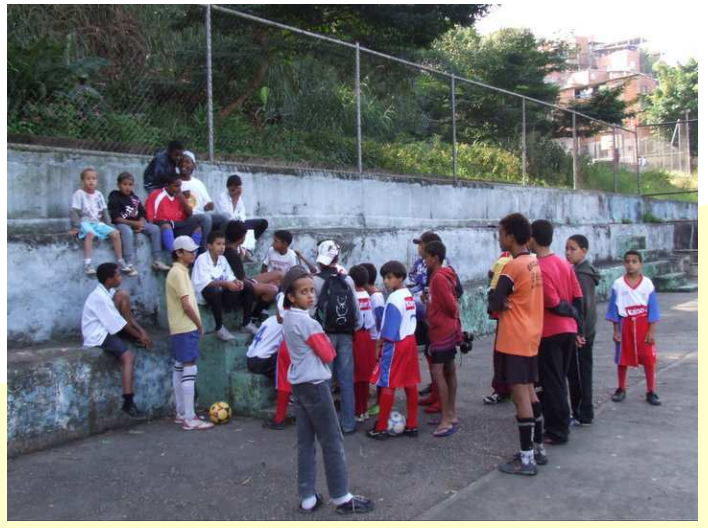

Fonte: http://vielaletraselivros.blogspot.com

Assim como nas quadras das escolas, a rua também foi palco dos jogos do Futebol \& Leitura. Neste caso também havia a exigência de adequação do espaço e da atividade, a Rua Macedônio Fernandez, que dá acesso à viela, possui um desnivelamento acentuado que impossibilita a realização da atividade. Já a Rua Faustino Allende, fazendo esquina com a anteriormente citada, apresenta declividade muito pequena e permitiu a execução dos jogos. A mesma configuração desta rua, uma das mais planas dentro da comunidade, serviu para quando a viela ficou pequena com a roda de leitura no dia em que o evento foi promovido em parceria com a Fundação Brasil Campeão ${ }^{4}$. A adequação do uso ao espaço se fez na premência de um lugar que oferecesse estrutura suficiente para abrigar a atividade, já os tapetes dispostos no chão, para maior conforto das crianças, mostra a adequação do espaço ao uso. Esta comunicação entre espaço e manifestação é característica fundamental para que as atividades propostas se tornem práticas efetivas

\footnotetext{
4 Fundada em 1999, no Jardim São Luís, pelo empresário Albert Holzhacker. A instituição atua em comunidades carentes do bairro de origem promovendo atividades ligadas à literatura infanto-juvenil.
} 
dentro das comunidades, pois elas sobrevivem da relação das boas ideias com o que há de disponível no ambiente para sua realização.

Futebol na Rua Faustino Allende.

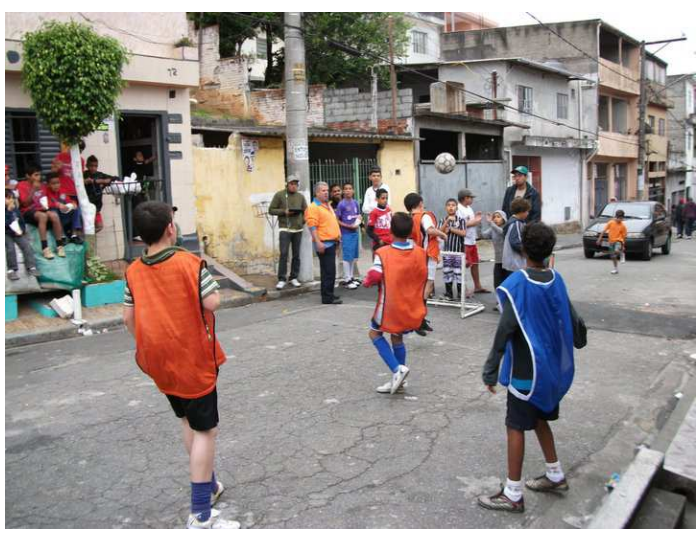

Fonte: http://vielaletraselivros.blogspot.com
Roda de leitura na Rua Faustino Allende.

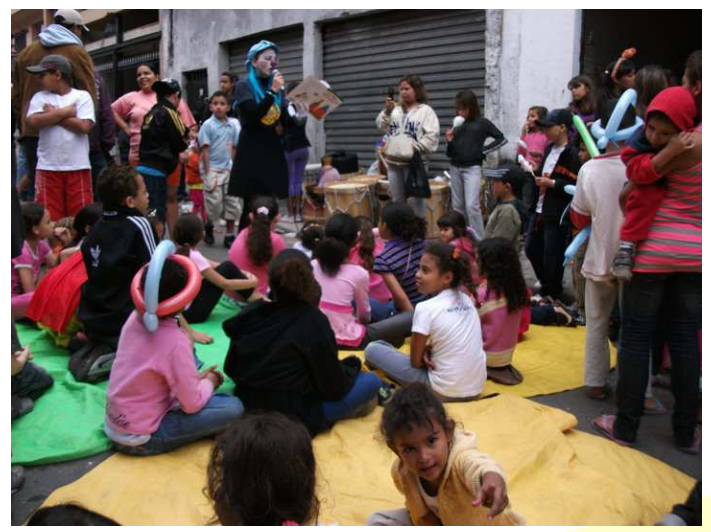

Fonte: http://vielaletraselivros.blogspot.com

A ONG Interferência mantém estas mesmas relações com o espaço da comunidade em que está inserida, porém o fato de possuir uma base das ações edificada e destinada exclusivamente aos seus usos permite que suas práticas permaneçam concentradas em seu entorno mais próximo. As atividades regulares executadas com as crianças ocorrem do lado de dentro e os eventos direcionados a toda a comunidade do lado de fora. A Travessa Santiago, onde está implantada, possui declividade quase inexistente e largura suficiente para que todos os eventos propostos ocorram nela mesmo, logo à frente da ONG. Desta maneira os idealizadores do projeto buscam expandir a maneira como lidam com espaço interior do prédio para fora, para o espaço público e coletivo da favela, em uma proposta de extensão de suas ações e, ao mesmo tempo, de apropriação para uma maior efetivação de sua atuação na comunidade.

Oficinas realizadas no interior da ONG.

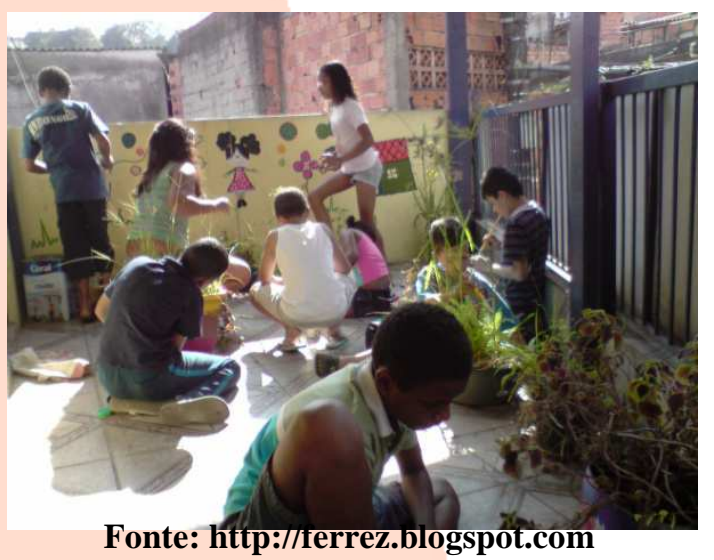

\section{Férrez (à esq.) com crianças em frente a} ONG.

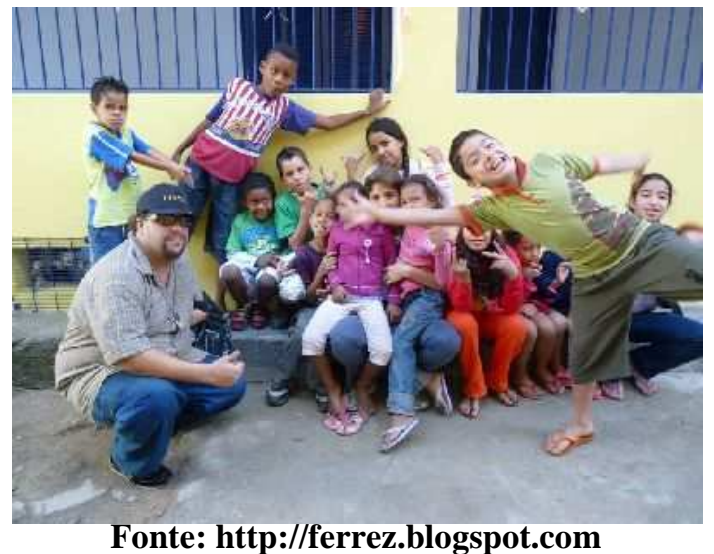

Reuista Anagrama: Reuista Científica Interdisciplinar da Graduação

Ano 6 - Edição 4 Junho - Agosto de 2013

Auenida Professor Lúcio Martins Rodrigues, ЧЧЗ, Cidade Uniuersitária, São Paulo, CEP: 05508-900 anagramąusp.br 
A Interferência, a partir do compromisso que assumiu em se tornar uma representação local, se responsabiliza em adequar o espaço em que atua de acordo com sua proposta de trabalho. Isto acontece quando os muros da travessa são pintados com figuras coloridas e os enfeites que as crianças produzem com material reciclado nas oficinas adornam postes e paredes. Com isso, as ações executadas dentro da comunidade assumem formas físicas que se integram ao espaço da favela em um processo de sedimentação da identidade comunitária do lugar.

Nova pintura na fachada da ONG.

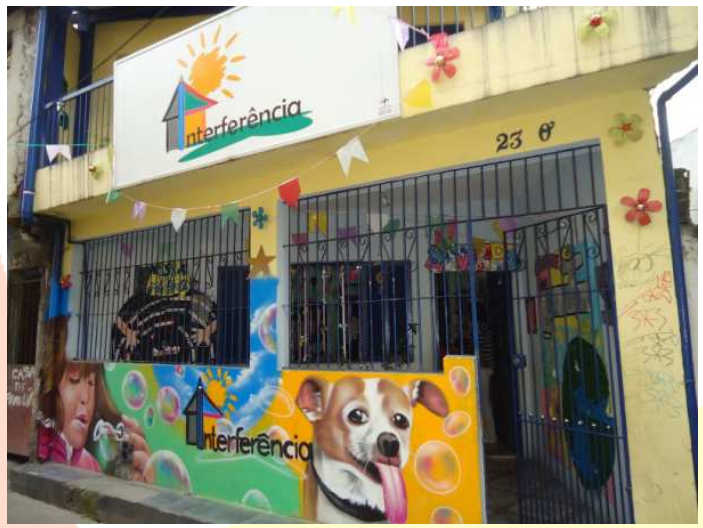

Fonte: http://ferrez.blogspot.com

\section{Comunidade auxilia na decoração da} travessa.

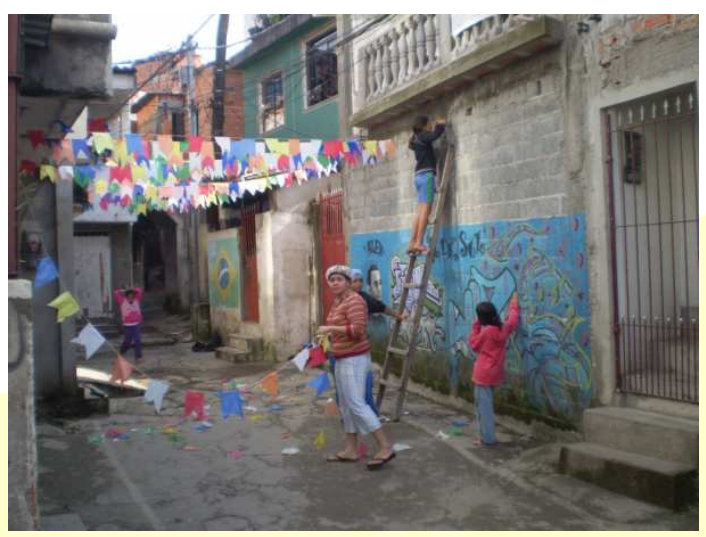

Fonte: http://ferrez.blogspot.com

O calendário de eventos que a ONG propõem para a comunidade considera sempre o envolvimento da população local em sua organização. A utilização de uma força de trabalho coletiva proveniente do lugar reforça a ideia do pertencimento, a responsabilidade é dividida junto com o sentimento de apropriação. Este núcleo que passa a abrigar o convívio cria uma esfera social entre a casa e a rua sobre o espaço da travessa, solidificando a proposta da Interferência em agir como ferramenta política-social associando o lugar à identidade da comunidade.

Estas ações e relações identificadas nos mostram pontos em comum, como a utilização da rua com a inserção de um novo significado; a presença de pessoas de diferentes pontos da favela que levarão a experiência obtida para dentro de suas e casas e para a vida comunitária; e a dinâmica de relações interpessoais e de adequações que permite a apropriação de espaços dentro da comunidade a partir das necessidades dos usos propostos. 


\section{Comunidade trabalha na organização do} evento.

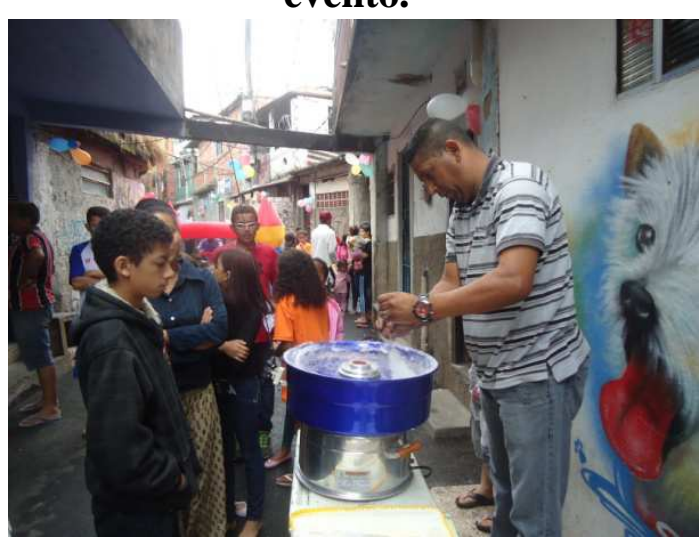

Fonte: http://ferrez.blogspot.com

\section{Comunidade auxilia na reforma da} ONG.

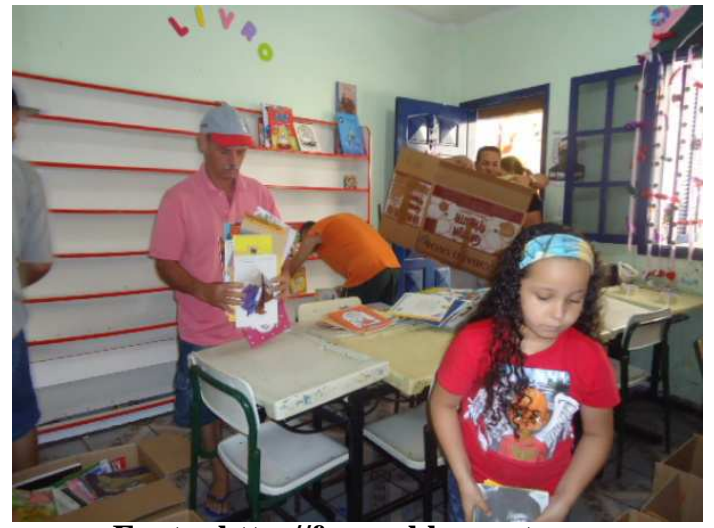

Fonte: http://ferrez.blogspot.com

\section{CONSIDERAÇÔES FIחAIS}

Identificamos diante desta pesquisa das manifestações de cultura promovidas por representações político-sociais dentro das favelas estudadas que os processos de apropriação do espaço urbano podem ser elencados em três etapas. (1) A necessidade de uma estrutura física que possa abrigar as atividades propostas e, desta maneira centralizadora, torná-las um referencial cultural para a comunidade demanda a apropriação inicial de um espaço que chamamos anteriormente de base das ações. Este lugar, ao receber a programação mais frequente e habitual de atividades assume o papel de polo, de onde partirão os demais processos de apropriação. (2) Com o objetivo de interferir na vida social da comunidade para além do já realizado e diante de novas propostas de atividades que os lugares inicialmente apropriados não compreenderiam, os idealizadores das manifestações lançam mão de espaços dentro do perímetro das favelas que possam atender esta primeira expansão das ações. Estes locais podem ser envoltórios à base ou estruturas específicas que atendam uma necessidade. (3) Uma segunda expansão, que segue os processos anteriormente citados, fica por conta da abrangência das manifestações dentro da comunidade, seja pela população que atinge ou pelos caminhos que ligam bases e atividades realizadas fora delas. Não se trata de uma apropriação física do espaço, mas de uma articulação de pessoas e percursos que expandem significados para além da parcela territorial apreendida na manifestação.

Fazendo uma analogia para a compreensão destes processos podemos imaginar uma superfície provida de sulcos desordenados, em um determinado ponto desta é despejado um líquido espesso que se esvai gradativamente pelas rugas. No caso das comunidades 
estudadas, o líquido, como manifestação de cultura que expande sua abrangência no lugar, ocorre de acordo com a relação entre a agenda de atividades proposta e a configuração dos espaços disponíveis para que se realizem. Isto acontece em uma relação dialética de adequação dos usos aos espaços e adequação dos espaços aos usos.

Cria-se então uma experiência de atuação sobre e apropriação do espaço urbano diversificada, que assumiu novas modalidades, adaptou-se a novas circunstâncias e estabeleceu outros diálogos com o lugar na tentativa de ressemantizar a cidade através da criação de espaços carregados de sentido, em busca da reanimação do espírito do lugar.

\section{REFERÊกCIAS BIBLIOGRÁFICAS}

DURHAM, Eunice Ribeiro. A Sociedade Vista da Periferia. In: L. Kowarick (org.), As Lutas Sociais e a Cidade. Rio de Janeiro: Paz e Terra, 1988.

FERRÉZ <http://ferrez.blogspot.com> Acessado em março de 2012.

FRÚGOLI JR, Heitor. O urbano em questão na antropologia: interfaces com a sociologia. Revista de Antropologia. São Paulo, vol. 48, nº 1, jan/jun 2005.

FUNDAÇÃO SEADE. Atualização de dados censitários da população moradora em favelas e loteamentos irregulares no município de São Paulo - relatório final. São Paulo, 2008.

GOOGLE MAPS <http://maps.google.com.br/>. Acessado em março de 2012.

HABISP. Mapeando a habitação na cidade de São Paulo. São Paulo: Boldarini Arquitetura e Urbanismo, 2008.

<http://www.habisp.inf.br>. Acessado em fevereiro de 2012.

JACOBS, Jane. Morte e vida de grandes cidades. São Paulo: WMF Martins Fontes, 2009.

LÉVI-STRAUSS, Claude. As estruturas elementares do parentesco. Petrópolis/São Paulo: Vozes/EDUSP, 1972. 
MAGNANI, José Guilherme Cantor. Festa no pedaço: cultura popular e lazer na cidade.

São Paulo: Brasiliense, 1984.

Transformações na cultura urbana das grandes metrópoles. In:

Moreira, Alberto Silva (Org.). Sociedade global: cultura e religião. Petrópolis: Vozes, 1998.

MARICATO, Ermínia. Metrópole na periferia do capitalismo: ilegalidade, desigualdade e violência. São Paulo: Hucitec, 1996.

NASCIMENTO, Érica Peçanha do. "Literatura Marginal”: os escritores da periferia entram em cena. Dissertação de mestrado em antropologia social. São Paulo: USP, 2006.

ONG INTERFERÊNCIA. ONG Interferência. Disponível em <http://www.youtube.com/watch?v=4ovA3xLg8mE>. Acessado em agosto de 2012. $<$ http://onginterferencia.blogspot.com.br>. Acessado em março de 2012.

ROLNIK, Raquel. O lazer humaniza o espaço urbano. In: SESC SP (Org.). Lazer numa cidade globalizada. São Paulo: SESC São Paulo/World Leisure, 2000.

SANTOS, Milton. Metrópole corporativa fragmentada: o caso da São Paulo. São Paulo: Nobel, 1990.

VIELA LETRAS E LIVROS. Viela Letras $e$ Livros. Disponível em <http://www.youtube.com/watch?v=_RfOrPXwzZE>. Acessado em março de 2012. $<$ http://vielaletraselivros.blogspot.com.br>. Acessado em março de

2012.

VILLAÇA, Flávio. Efeitos do espaço sobre o social na metrópole brasileira. VII Encontro Nacional da ANPUR. Recife, 1997. Disponível em <http://www.flaviovillaca.arq.br/pdf/efeitos96.pdf>. Acessado em fevereiro de 2012. 